\title{
The Research on Service Platform of Ship Manufacturing in Cloud Manufacturing Environment
}

\author{
Xiang Su ${ }^{1}$,Liang-liang Gao ${ }^{1}$, Wei-yong Wang ${ }^{2}$, Lai Wei ${ }^{1}$ \\ ${ }^{1}$ School of Management \& Economics, Jiangsu University of Science and Technology, Zhenjiang 212003, China \\ ${ }^{2}$ Shanghai Waigaoqiao Shipbuilding Co., Ltd., Shanghai 200000, China
}

\begin{abstract}
Through the analysis about the present situation of ship manufacturing industry informatization, introduces cloud manufacturing. The construction of the ship enterprise manufacturing service platform in the cloud manufacturing environment is studied. Detailedly describes the function of each module and build ideas. The key technology involved service platform is introduced, describes in detail the operation process of the service platform of ship manufacturing in cloud manufacturing environment. The service platform of ship manufacturing in cloud manufacturing environment for the realization of a certain region to maximize resources and manufacturing taskshipbuilding fast matching has important significance.

Index Terms - cloud manufacturing, informatization, the service platform
\end{abstract}

\section{Introduction}

Nowdays, China has become a big shipbuilding country, but there is still a large gap between China and the other shipbuilding powers such as Japan, Korea, the United States and Europe[1].To shorten the distance with advanced shipbuilding powers, further promoting the shipbuilding informatization is undoubtedly the only way. At present, information technology has gradually infiltrated each link of value chain of shipbuilding. However, there are still following problems in the shipbuilding informatization in China:(1) Enterprise information integration is low. (2) the development of shipbuilding enterprise is uneven.(3) the level of information in parallel and cooperative is low. The introduction of the concept of cloud manufacuring has further promoted the inforamatation and intellectualization of shipbuilding enterprise.

Based on the concept of "Manufacture as a Service", cloud manufacturing draws on the new manufacturing model which is developed by the idea of cloud computing[2]. Cloud manufacturing is a network-oriented collaborative manufacturing model, inheriting the common features of networked manufacturing such as agile response, resource sharing, collaborative design and manufacturing, taking over the basic characteristics of cloud computing such as scale, low-cost and high flexibility[3]. Comparing to the existing network manufacturing and manufactruing grid[4], cloud manufacturing has advantages such highly opened paltform and highly compatible resources. The introdution of cloud manufacturing in shipbuilding enterprise will maximize the integration of the resources of each shipbuilding enterprise in the whole area, which can not only significantly reduce shipbuilding cycle, but also have positive effcets on promoting business collaboration of regional shipbuilding enterprise group and industrial chain, supporting optimal configuration of regional and manufacturing resources, achieving rapid response to business orders and promoting the improvement of regional shipbuilding enterprise's collaboration and regional competitiveness.

\section{Shipbuilding Services Platform in Cloud Manufacturing Environment}

\subsection{Overview of shipbuilding services platform in cloud manufacturing environment}

Shipbuilding cloud manufacturing refers to organize the virtualized manufacturing resources (manufactured cloud) according to the specific needs of ship-owners or ship enterprises with the help of network and cloud manufacturing service platform, and on demand to supply networked manufacturing new models of various types of shipbuilding services. The core idea of the model is to achieve the transformation and upgrading from product-oriented manufacturing to service-oriented manufacturing, namely the development models of shipbuilding enterprises are changed from the traditional model which is recognized product manufacturing as the core to the new model which should provide integrated services based on product.

The Shipbuilding services platform in cloud manufacturing environment is based on network manufacturing and service platform of service provider, use cloud manufacturing services model provides all types of readily available, on-demand, safe and reliable, high-quality and low-cost shipbuilding services. Compared to the existing service providers and networked manufacturing platform, the collaboration scope of this platform is more extensive which can permeate to every stage of full life cycle of shipbuilding, it is a platform which provide the deep manufacturing services and maintenance. The service platform can be divided into six layers as shown in Figure 1. 


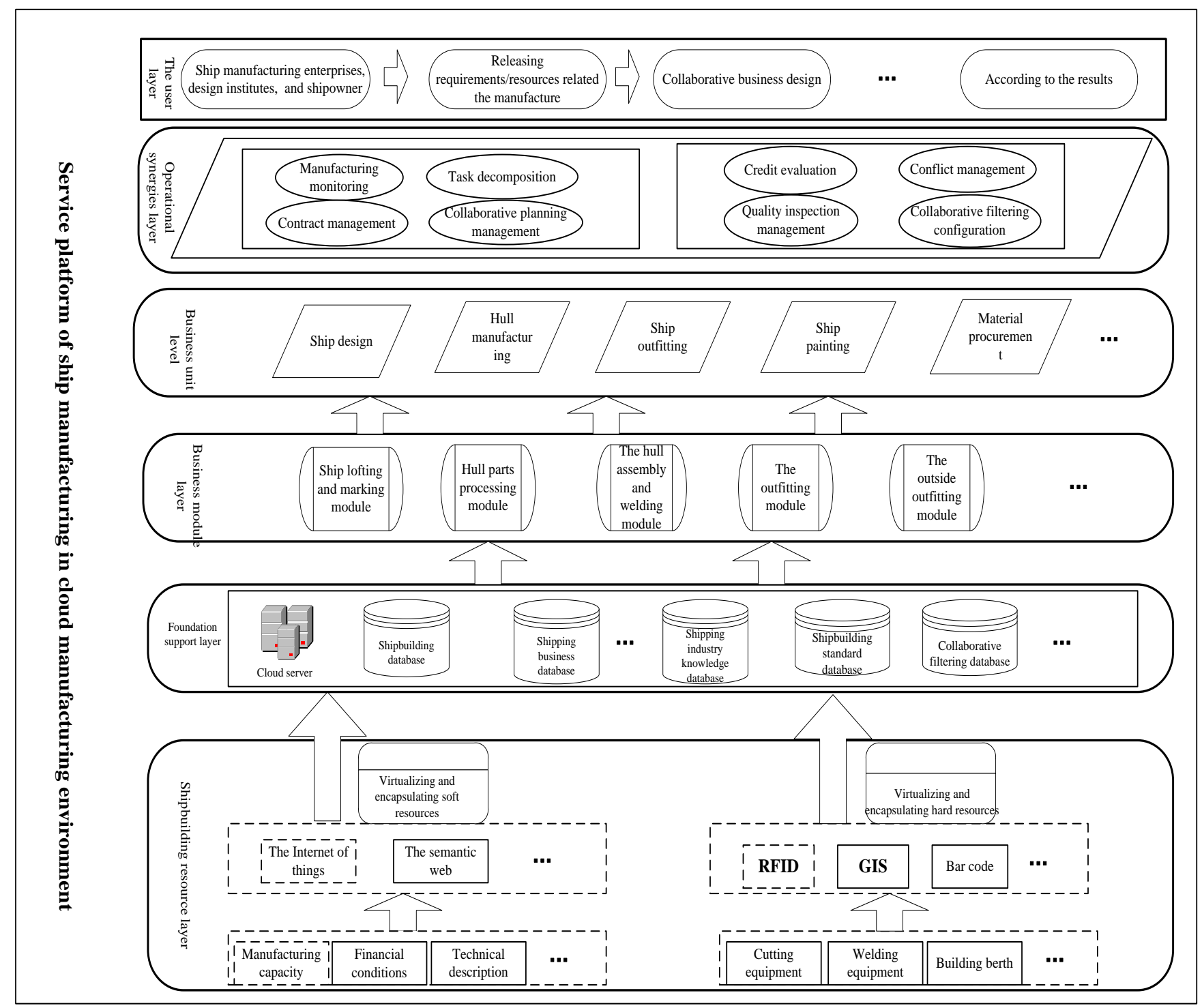

Fig.1 Service platform of ship manufacturing in cloud manufacturing environment

\subsection{Functional description of shipbuilding services platform in cloud manufacturing environment}

A Resource layer. In this layer, a variety of resources that involved in the process of shipbuilding services platform are provided, the current classify of resources is quite a lot. In this article, the resources will be divided manufacturing resources into soft resources (technical information, knowledge, resources etc.) and hard resources (manufacturing equipment, slipway etc.).The platform will virtualize and package collected and all types of heterogeneous resources and access them to cloud services platform for unified management and scheduling by using the RF Technology and Internet of Things [5] and some other physical related virtualization technologies.

B Basic support layer. This layer includes basic data resources that are required to run the platform, such as ship industry-standard data, and other ship business data. In addition, the basic support layer also provides various types of engines, interfaces, management tools, specifications, and development tools. Where engine includes transaction coordination logic engine, knowledge gathering and classification engine, business process management engine, cloud service management and support engine.

C Business module layer. Business module layer provides the business module after resources integration in the process of shipbuilding. So-called resources integration is that when the platform has received the shipbuilding demands of demanders, it will make selection,matching and optimization combination for resources according to the characteristics of the ships made,thus form a business module that can be 
directly converted into manufacturing capability. This layer mainly includes ship lofting and marking module, hull parts processing module, hull assembly and welding module, inside and outside the outfitting module, and so on. Meanwhile, business module layer is the basic support module of business unit layer, providing callable business module service for business unit layer.

D Business unit layer. This layer are those sets which provide demanders with all businesses involved in the process of shipbuilding, including shipbuilding design, manufacturing, ship hull outfitting business,etc. Shipbuilding design business units include all businesses related design includes ship owner's contract designing, production plan designing,etc. Manufacture business unit contains various businesses related manufacture, such as ship manufacturing process management, production plan execution,etc.According to the specific needs of shipbuilding,cloud manufacturing service platform business unit will be carried out in the allocation of resources and build the business process, thus prepare for subsequent order processing,production plan making and production process executing.

E Operational synergies layer. Design process of management by shipbuilding collaborative, monitoring the process of collaborative design. You must detect various types of conflict in the process. of collaborative design and submit it to the module of conflict resolution for digestion. When we completed collaborative manufacturing, you need rate shipbuilding's credit. Include credit assessment, conflict management, manufacturing control[6], task decomposition, contract management, in consultation with program management, in collaboration with the manufacturer filter configuration, quality inspection management module.

F User layer. User layer that provides a user interface to access and browse an interactive service and user requirements service to registration issue. Cloud manufacturing platform users include the related manufacturers, design institutes, such as classification societies, ship owners, this feature will go through different manufacturing platform for interaction between Terminal user and clouds, efficient synergies and support the main tasks, It become an efficient platform of information interaction between the user and the system.

\section{Pivotal Technology of Platform}

\subsection{Service-oriented architecture}

Service-oriented architecture (Service-Oriented Architecture, SOA) is a design principle, which is usually used in the phase of computer integration and the phase of software development[7].SOA is a component model, combinating the different functional units of the application (called services) through well-defined interfaces and contracts. These interfaces are defined in a neutral manner and they are independent of the hardware platform of services, programming languages and operating systems so that services built in different systems can interact in a uniform and universal way. The introdution of SOA can help system to break the limitation of heterogeneous platforms and to achieve loose coupling of collaborative design with the portability, openness and scalability.

\subsection{Virtualization}

For the user or upper layer applications, virtualization is a concept abstracting computing resources which package the underlying property of the computing resources, either divide a single resource (such as an application, a storage device, a a server, an operating system)into multiple virtual resources, but also can integrate multiple resources into a single virtual resource[8]. Therefore, virtualization technology can be used to shipbuilding equipment, welding equipment, manpower and other resources for abstract plans under cloud manufacturing mode.

\subsection{Integrated management technology of manufacturing cloud services}

The main research of integrated cloud service management technologies, including access management of cloud resources and services provider; efficient, dynamic cloud services formation, aggregation, storage methods; efficient, intelligent and dynamic cloud manufacturing services dynamic matching technology; cloud manufacturing tasks dynamically build and deploy, decomposition, optimize the allocation of resources services cooperative scheduling method; cloud manufacturing service delivery model and marketing, cloud users (including cloud provides cloud-side and client request) management and authorization mechanisms.

\subsection{Collaborative conflict resolution}

Shipbuilding collaborative process is a complicated systems engineering, collaborative design process will produce inevitably conflict [9-10], and exit many kinds of conflict, in product design, relying on a single project can not be a comprehensive solution to resolve variety of complex conflicts. Research on the causes, characteristics and categories of collaborative manufacturing under services platform, and based on the current status of research of conflict resolution, develop the conflict resolution model to match the cloud manufacturing collaborative design platform, establish impeccable conflict management mechanisms.

\section{Platform Running Mode}

Under the mode of cloud manufacturing, the users who needs ship manufacturing business don't need looking for manufacturing services provider, and face-to-face open negotiations with the provider, only need to submit needs to the cloud manufacturing service platform,then the service platform will organize resources to meet the requirements of service, and automatically assigned corresponding resources to complete the design work. The operation mode of the service platform of ship manufacturing in cloud manufacturing environment is shown in figure 2 .

Its operation process is as follows: 


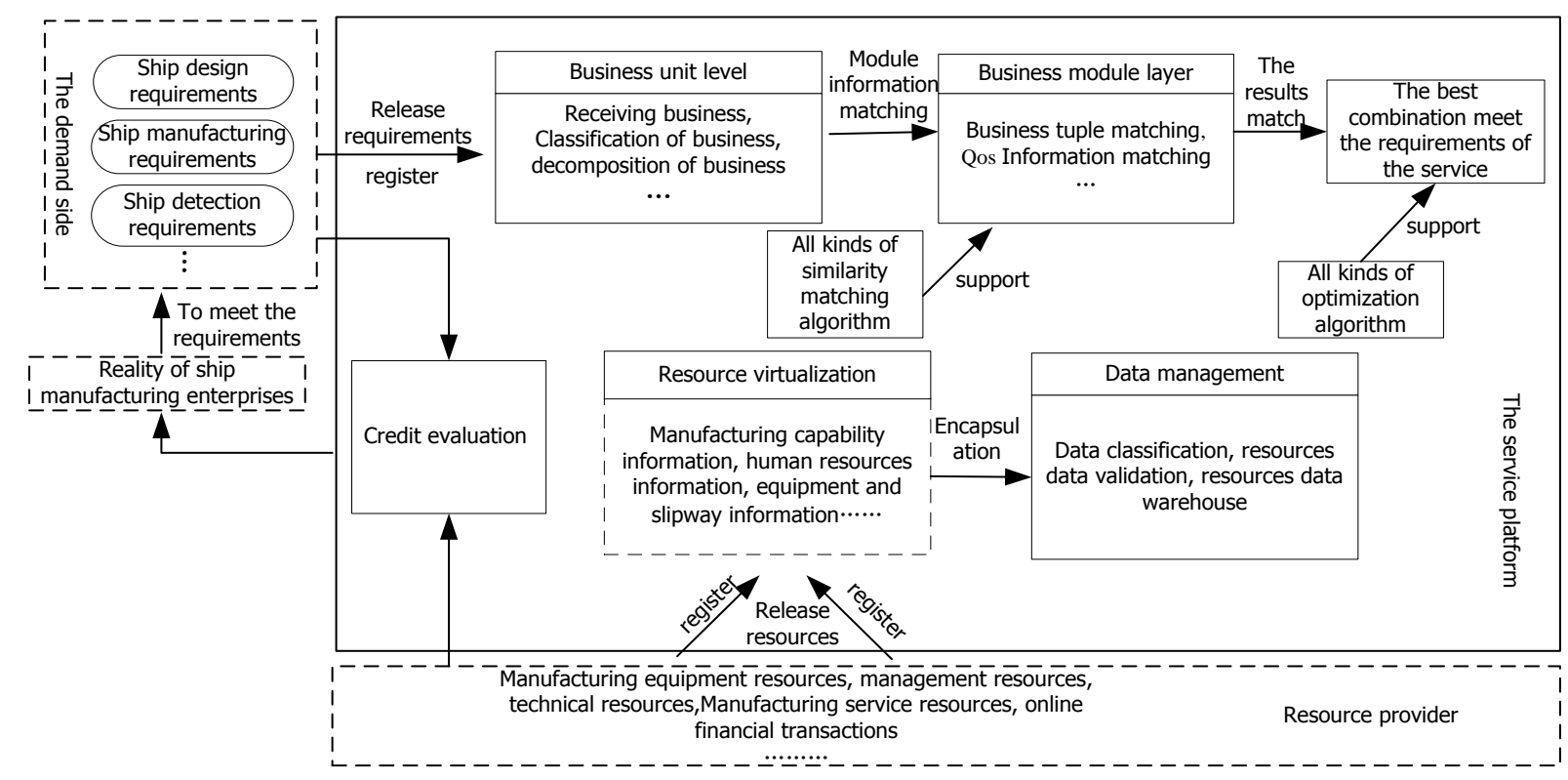

Fig.2 Platform running mode

Business demanders(ship owners,etc.) and the provider of resources (related manufacturing enterprises who can provide resources), register on the user layer of the plamfort and different types of users can register different user service.Its own resources can be released after registration of resource provider.Then the platform will make use of the Internet of things, such as RFID technology to virtualize and encapsulate resources. The data encapsulated will be classified and stored in the cloud database and called to prepare for the resource. Business demand-side describe collaborative manufacturingrelated tasks, identify resources and screening evaluation indicators for resource providers to perform required tasks through the user-level portal; the platform will decomposite and classify a service request providing by business demanders at the business unit level; After classifying, the platform will automatically match business group services and optimize resource services portfolio in the business module layer, then provide business demanders with optimal resource services portfolio.In reaching the optimal combination of manufacturing, services portfolio will be passed to real companies. Real companies will get the virtual demand into actual demand and start to produce, and real-time monitoring and feedback through the manufacturing business collaboration platform services layer, real-time elimination conflicts arising from collaborative manufacturing process, until meet the requirements of the business demand-side; After the completion of the manufacturing business, credit evaluation will be done on both sides.

\section{Conclusions}

Cloud manufacturing mode has a broad prospect in shipbuilding, and it is very significant for our country to be the powerful shipbuilding country in the world.If it can be successfully used in shipbuilding, it will work in speeding up integration of industry resources, shortening the life cycle of ship designing and manufacturing, reducing the cost. However the present research stays on the conceptual level of the shipbuilding service platform under cloud manufacturing environment.The further research should pay close attention to the basic theory of its operation, key technology, process management and product quality controlling and so on. It is shoulder heavy responsibilities for the researchers and manufacturing enterprise to apply the theory in practice successfully.

\section{References}

[1] Zhang Weifeng, lu Kaidong. Shipbuilding industry development trend and the enterprise production and operation suggestion of China. Journal of Marine engineering, 2013, 35 (2), pp.1-5

[2] Yang Haicheng. Cloud manufacturing is a kind of manufacturing services. Manufacturing industry informationization of China, 2010, 33 (6), pp. 22 - 23

[3] Li Bohu, Zhang Lin, Wang Shilong, etc. Cloud manufacturing-serviceoriented networked manufacturing new model. Journal of computer integrated manufacturing system, 2010, 33 (6) pp.22 - 23

[4] Su Shijie, Zhou Honggen, Fang Xifeng. Ship life-cycle information system based on data grid research. Journal of China shipbuilding, 2011, 52 (2), pp.180-188

[5] Li Guangzheng, Wang Tao, Zhang Guoyong. Intelligent ship design based on Internet of things system. Journal of Marine engineering, 2012, (6), pp.59-62

[6] Zhao Xiaolan, Guo Yongshang, Xu Jiren, Li Changchen, Chen Gusong. The development and current situation of the monitoring data analysis technology for ship. Journal of China shipbuilding, does 2012 (4) pp.198-207

[7] Li Chunquan, ShangYuLing, Hu Chunyang. Cloud manufacturing architecture and its key technology research. Combination machine tools and automatic processing technology, 2011,pp.104-113

[8] Zhang Qian, Qi Deyu. Service-oriented cloud manufacturing collaborative design platform. Journal of south China university of technology: natural science edition, 2011, 33 (12) pp.75-81

[9] Liu Yindong, Su Shaojuan. Parallel collaborative design environment and the key technology of ship. Journal of dalian maritime university, 2011, 37 (1) pp.25 to 28.

[10] Wang Yue, Ju Yangli, Jiang Zhiyong, Liu Jianfeng. Research on ship design process based on the theory of the parallel collaborative. Journal of Marine engineering, 2013, 35 (5) pp. 96-99 